\title{
AS PESSOAS COM DEFICIÊNCIA NO CONTEXTO DA EDUCAÇÃO ESCOLAR BRASILEIRA
}

\author{
Roseane Rabelo Souza Farias ${ }^{1}$ \\ Thais Andrea Carvalho de Figueirêdo Lopes ${ }^{2}$
}

\section{RESUMO}

As políticas educacionais brasileiras, em especial as que tem atenção às pessoas com deficiência, tem motivado uma série de pesquisas e estudos acadêmicos. $\mathrm{O}$ presente artigo analisa os principais condicionantes históricos e políticos da educação para essas pessoas, tendo como eixo a contextualização da educação como um direito que leva à formulação e à implementação de políticas públicas que não tem atingido a todos. Mostra-se que o direito à educação tem sido negado a uma parte significativa da população brasileira, incluindo as pessoas com deficiência.

Palavras-chave: Direito à Educação; Pessoas com Deficiência; Políticas Educacionais.

\section{PEOPLE WITH DISABILITIES IN THE CONTEXT OF BRAZILIAN SCHOOL EDUCATION}

\begin{abstract}
Brazilian educational policies especially those that have attention to people with disabilities has motivated a lot of researches and academic studies. This article analyzes the main historical and political conditions of education for these people taking as a center line the contextualization of education as a right that leads to the formulation and implementation of public policies that have not reached everyone. It is shown that the right to education has been denied to a significant part of the population including people with disabilities.
\end{abstract}

Keywords: Right to Education, People with disabilities, Educational Policies.

\section{INTRODUÇÃO}

A educação no Brasil como um direito de todos é afirmada na Constituição Federal de 1988, o que possibilitou importantes conquistas relacionadas ao acesso à escola. Em seguida a esse marco legal que rege as demais leis em nosso país foi promulgado o Estatuto da Criança e do Adolescente, Lei n. 8.069/1990, que também afirmou o direito à educação para todas as crianças e adolescentes brasileiros. Na mesma década, a Lei de Diretrizes e Bases da Educação Nacional, Lei n. 9.394/1996, definiu os níveis e modalidades da educação, especificando a competência da oferta de cada ente federado.

Contraditoriamente ao disposto nos textos legais, a instituição de uma política de fundos para financiar a educação no Brasil, privilegiando durante uma década apenas o ensino fundamental, com a implementação do Fundo de Manutenção e Desenvolvimento do Ensino Fundamental e de Valorização do Magistério (FUNDEF), em vigência na década de 1996-2006, não permitiu os avanços esperados nas outras etapas e modalidades da educação básica, pois somente em 2007 toda a educação básica passou a ser contemplada pelos recursos provenientes do Fundo de Manutenção e Desenvolvimento da 
Educação Básica e de Valorização dos Profissionais da Educação (FUNDEB), previsto para durar até 2020.

Isso significa que o direito à educação para todos está estabelecido na legislação; entretanto, quando se tratou de assegurar esse direito por meio do financiamento da escola pública, as decisões governamentais não corresponderam à efetivação desse mesmo direito.

Com relação à educação escolar das pessoas com deficiência, sabe-se que esse atendimento foi realizado primeiramente em instituições especializadas de caráter privado e, mesmo quando a educação especial passou a fazer parte do rol do direito à educação pública, as instituições privadas continuaram atuando nessa área, ainda que no cenário atual já existam matrículas nas escolas regulares municipais e estaduais, com a garantia do atendimento educacional especializado em salas de recursos multifuncionais.

Para compreender como a educação escolar das pessoas com deficiência vem se constituindo historicamente é necessário analisar os avanços das concepções acerca da deficiência, relacionando-os com a contextualização da educação como política pública em um país capitalista, no qual via de regra os direitos que deveriam ser de todos são negados a grande parte da população.

\section{AS CONCEPÇÕES DE DEFICIÊNCIA: DA NEGAÇÃO À AFIRMAÇÃO NOS DIREITOS HUMANOS:}

As pessoas com deficiência têm sido classificadas e tratadas de diferentes maneiras e é inegável que tais formas de tratamento geram um corte ontológico significativo, que muitas vezes as diferenciam de outras pessoas sem deficiência, desvalorizando-as. Gatjens (2007) afirma que há uma relação entre a forma como as pessoas com deficiência são vistas em nossa sociedade, geralmente de forma depreciativa, pautada pelo preconceito e a violação de seus direitos humanos. A expansão dessa violação foi atribuída à própria pessoa com deficiência, alegando-se seu suposto afastamento de um modelo questionável de normalidade. $\mathrm{O}$ autor apresenta três modelos ou paradigmas de compreensão da deficiência e sua relação com o exercício e a garantia dos direitos humanos; conhecer esses modelos torna-se necessário para compreender a evolução do conceito de deficiência.

O primeiro paradigma vem desde a Antiguidade e é intitulado tradicional; considera a pessoa com deficiência como um ser inferior que tem sua existência marcada pela raridade ou anormalidade, sujeito de compaixão e não de direitos, devendo ser tutelado por outras pessoas por meio da caridade, pública ou privada. Nesse modelo, a dignidade do ser humano é desrespeitada e os preconceitos que afetam as pessoas com deficiência se perpetuam na sociedade contemporânea. Alguns autores denominam esse momento histórico de modelo Caritativo (AUGUSTIN, 2012).

Já no segundo modelo, cognominado médico, a deficiência é conceituada como um problema e a pessoa com deficiência é vista como objeto de atendimento e intervenção clínica. Sendo assim, para compensar suas limitações funcionais, necessita de uma equipe de profissionais e especialistas, capazes de propiciar serviços e tratamentos visando à sua cura. Nesse enfoque, a pessoa é vista como um receptor passivo de apoios institucionalizados e não como um sujeito de direitos.

Por fim, Gatjens (2007) anuncia o paradigma de direitos humanos, em que a pessoa com deficiência é considerada como sujeito de direitos, em oposição aos modelos que a viam como objeto de assistência e reabilitação. Esse paradigma evidencia a dignidade do ser humano ao postular que a deficiência é gerada ou agravada pelo entorno sociocultural e 
físico da pessoa, cabendo ao Estado à responsabilidade de realizar ações para contrapor-se aos obstáculos criados socialmente.

$\mathrm{Na}$ esteira das concepções desenvolvidas no último paradigma, destaca-se o modelo social, do qual Colin Barnes foi um de seus fundadores. Assumir uma positividade discursiva em relação à deficiência tem sido o principal objetivo desse modelo, que busca sobrepujar a compreensão da deficiência ancorada no discurso biomédico, centrado nos impedimentos corporais. Barnes (2010) afirma que todas as pessoas são, potencialmente, deficientes, pois a deficiência é consequência de fatores sociais e políticos e não um inevitável acontecimento natural.

Com a redefinição do conceito de deficiência no modelo social, foi transferida do indivíduo a responsabilidade de ser inadequado, para a incapacidade social de prever e incorporar a diversidade, em que a deficiência pode ser politicamente definida como opressão social e não como tragédia pessoal. Aceitar a deficiência como uma questão não só do indivíduo mas também de seu entorno requer transpor o julgamento da deficiência pela falta enfatizada pelo modelo médico e isso implica a realocação das discussões da deficiência do campo médico para o campo dos direitos humanos.

O conceito de deficiência no modelo social vai além da lesão e denuncia a estrutura social que oprime a pessoa deficiente, passando a deficiência a ser pactuada em termos políticos e não mais exclusivamente em termos diagnósticos. A intenção é superar os eufemismos discriminatórios, expressões ainda vigentes no léxico ativo (DINIZ, 2013).

Na concepção de Barnes (2010) a sociedade torna as pessoas deficientes e propicia experiências de desigualdade vivenciadas pelas pessoas com impedimentos em uma sociedade pouco sensível à diversidade. A deficiência ainda é configurada como uma variação da normalidade, carregada de um julgamento estético.

Nessa outra perspectiva de pensar a deficiência, o objetivo não é negar a realidade do impedimento, ignorando os cuidados médicos ou a reabilitação, que é algo necessário a todos, com ou sem deficiências, e sim suscitar o entendimento de que ter uma deficiência não significa ser inferiorizado. De fato, reconhece-se que ainda existe no Brasil a influência do modelo biomédico sobre o conceito de deficiência, quando essa continua a ser acreditada como uma questão individual e não como uma questão de organização e justiça social que demanda políticas sociais.

Muitos trabalhos contribuíram para a evolução do conceito de deficiência e para os avanços na educação das pessoas com deficiência. Médicos como Jean Itard (1774-1838), Edouard Séguin (1812-1880) e Maria Montessori (1970-1952) marcaram a educação especial ao se proporem a educar crianças tidas como fora dos padrões de normalidade, tentando combater as ideias propostas pelo inatismo.

Em seguida, a psicologia experimental e a psicometria por meio dos laudos psicológicos e testes de inteligência passaram a fazer parte das avaliações e diagnósticos das crianças com deficiência, tendo Alfred Binet (1857-1911) como um de seus principais expoentes. Na década de 1930 ocorreu uma ampla divulgação desses testes para a identificação dos anormais com o objetivo de formar classes homogêneas nas escolas, quando Helena Antipoff (1892-1974) e suas ideias começaram a ocupar lugar de destaque no cenário nacional.

Durante muito tempo os usos dessas contribuições da psicologia serviram para classificar, rotular e segregar as crianças com deficiência intelectual. Patto analisa que a cruzada psicométrica do começo do século XX, a "teoria" da carência cultural (grifos da 
autora) e o conceito de aptidão natural fazem parte da "necessidade de auto-explicação da sociedade capitalista em termos que garantam a sua continuidade (a sua reprodução)" (1997, p.6). De acordo com a autora o encaminhamento das escolas para a realização de exames psicológicos terá diferentes resultados dependendo da classe social da criança diagnosticada, pois as crianças pertencentes a uma classe economicamente mais favorecida serão levadas a "psicoterapias, terapias pedagógicas e orientação de pais que visam adaptálas a uma escola que realiza os seus interesses de classe" (Patto, 1997, p.1) e a criança oriunda da classe economicamente menos favorecida "termina com um laudo que, mais cedo ou mais tarde, justificará a exclusão da escola" (Idem).

A pedagogia e as formas de ensinar e aprender foram incorporadas mais evidentemente a partir dos estudos decorrentes da psicologia como as obras de Piaget (1896-1980), Vigotski (1896-1934) e Wallon (1879-1962). Como se pode notar, os pressupostos desses teóricos continuam subsidiando a ação pedagógica com crianças com e sem deficiência, sob as mais diversas apreensões e interpretações dessas teorias.

Os laudos e testes psicológicos de inteligência continuam sendo utilizados em detrimento de uma avaliação pedagógica que pudesse identificar as potencialidades do aluno e não somente a anormalidade, as incapacidades, as limitações e o que o aluno não faz e não pode fazer, ou seja, vê-se que houve pouco avanço da pedagogia brasileira na avaliação desses alunos no sentido de criar condições favorecedoras da inclusão dessas crianças na escola comum.

\section{AS CONTRADIÇÕES DAS POLÍTICAS SOCIAIS, A VULNERABILIDADE DOS DIREITOS SOCIẢIS E AS PESSOAS COM DEFICIÊNCIA}

A manutenção da ordem social na qual a exploração dos trabalhadores pelos donos dos meios de produção e da propriedade privada gera a desigualdade é a mola propulsora da engrenagem do sistema capitalista, embasada pelos preceitos neoliberais de redução do papel do Estado e de livre concorrência no mercado. Nesse sentido, para que possa haver uma coexistência social razoável no capitalismo, é necessário que haja uma regulamentação por meio das leis, dos direitos formais e dos mecanismos de reivindicação desses direitos visando à chamada justiça social.

Para esse alcance faz-se necessária uma série de negociações em uma sociedade dividida em classes sociais, com interesses, propósitos e valores distintos, ou seja, discutir justiça no capitalismo será sempre aceitar a premissa da dominação do homem pelo homem, ainda que isso signifique melhoria das condições de vida para alguns.

Diante da perda da garantia de direitos sociais, estão postos então os alicerces para a construção e implementação das políticas sociais focalizadas, em detrimento das políticas sociais universais. A polêmica entre a defesa de políticas sociais universais ou focalizadas nem sempre evidencia o afastamento cada vez maior da transformação de uma sociedade desigual e injusta, em uma sociedade mais justa e igualitária, a partir da implementação de políticas universais. Todos têm os mesmos direitos, inclusive as pessoas com deficiência, de terem suas necessidades específicas atendidas. Ocorre que a defesa dos direitos das pessoas com deficiência tem sido feita por meio da reivindicação de políticas sociais focalizadas, sob a argumentação do atendimento às necessidades específicas dessas pessoas. Se essa reivindicação fosse mais ampliada e abrangesse o direito de todos, não avançaríamos também em direção ao atendimento as pessoas com deficiência? 
Conforme Carneiro e Souza (2007), tem se proliferado iniciativas afinadas com uma perspectiva compensatória, enviesada por um assistencialismo precário que elege grupos minoritários como alvo da focalização. Segundo os autores, a focalização pode representar, muitas vezes, uma resposta engenhosa diante da escassez de recursos públicos, mas não possibilita sequer o equacionamento dos graves problemas sociais.

É bem verdade que grupos específicos como as pessoas com deficiência têm necessidades próprias que precisam ser atendidas para que possam exercer sua cidadania, mas também é verdade que pobreza pode gerar deficiência, quando se sabe que uma parcela significativa das pessoas com deficiência é pobre, o que torna mais difícil o atendimento das suas necessidades.

Diante disso, Gatjens (2007) afirma a existência de um círculo vicioso, em que deficiência gera a pobreza e as condições de pobreza potencializam o risco de adquirir uma deficiência, ou seja, as pessoas com deficiência têm mais possibilidades de serem pobres e de permanecerem em situações de pobreza, em virtude dos custos dos serviços de saúde e reabilitação. Tal situação deveria ser objeto de preocupação do poder público, entretanto, a situação das pessoas com deficiência no contexto dos direitos sociais continua desfavorável.

De acordo com a Cartilha do Censo 2010 - Pessoas com Deficiência (2012), 45.606.048 brasileiros têm algum tipo de deficiência, ou seja, esse número corresponde a $23,9 \%$ da população total. A deficiência visual é a de maior prevalência, atingindo 18,6\% dessas pessoas. Em seguida, a deficiência motora ocorre em 7\% da população, a deficiência auditiva em $5,10 \%$ e a deficiência mental ou intelectual em $1,40 \%$. É possível verificar que $8,3 \%$ da população brasileira apresentava na ocasião pelo menos um tipo de deficiência severa, sendo que 3,46\% tinham deficiência visual severa, 2,33\% deficiência motora severa, $1,12 \%$ deficiência auditiva severa e 1,4\% deficiência mental ou intelectual severa.

Ao analisar os dados das regiões brasileiras constata-se que a maior prevalência de pessoas com deficiência é na Região Nordeste desde 2000, quando a taxa já era a maior comparando as regiões, $16,8 \%$ naquele ano e $26,3 \%$ em 2010. Na sequência, em 2010, a Região Norte aparece com 23,40\%, a Região Sudeste com 23,03\%, a Região Centro-Oeste com 22,51\% e a Região Sul com 22,50\%. Os Estados do Rio Grande do Norte, com $27,76 \%$ e da Paraíba com 27,58\%, são os de maior incidência de deficiência e as taxas mais baixas de existência de pessoas com deficiência estão no Estado de São Paulo, 22,6\% e no Distrito Federal, 22,3\%.

Mesmo concordando que os mecanismos censitários precisam de aperfeiçoamento, as estatísticas ora apresentadas são importantes fontes de consulta e de inferências. Se a Região Nordeste está em destaque em 2000 e 2010 como a região com maior percentual de pessoas com deficiência e também é considerada a região brasileira na qual estão alguns dos estados e municípios mais pobres do Brasil, a relação pobreza/deficiência evidencia-se nessa situação.

Conforme o documento citado, a taxa de alfabetização da população brasileira em 2010 foi de $90,6 \%$, e a mesma taxa das pessoas com pelo menos uma das deficiências foi de $81,7 \%$. No mesmo ano, as Regiões Norte e Nordeste tiveram as menores taxas de alfabetização, para as pessoas com e sem deficiência. Já em relação ao nível de instrução das pessoas com deficiência, em 2010 ainda havia $61,1 \%$ dessas pessoas sem instrução e ensino fundamental completo, $14,2 \%$ possuíam o ensino fundamental completo, $17,7 \%$ o ensino médio completo e $6,7 \%$ o ensino superior completo. $\mathrm{O}$ índice das pessoas sem 
deficiência sem nenhuma instrução e com ensino fundamental incompleto ficou em 38,2\%, também em 2010.

A Região Nordeste também aparece com o maior percentual de pessoas com deficiência sem instrução e com fundamental incompleto, 67,7\%. Observa-se que apesar da inclusão das pessoas com deficiência na escola comum, um grande contingente ainda está fora desse espaço.

Uma parcela significativa de pessoas com deficiência, entre elas crianças e adolescentes, tem seus direitos à educação violados, uma vez que, são excluídas dos sistemas educativos. Gatjens (2007) chama atenção para o fato de que o acesso depende do tipo e grau de deficiência, já que a recusa a crianças com deficiências graves tem sido uma constante em diversos países, a exemplo da América Latina, onde são corriqueiros os casos de crianças com deficiências que não avançam além do ensino fundamental.

De acordo com o autor, isso revela fragilidades na efetivação dos direitos humanos, o que demonstra que a presença de instrumentos legais não tem sido suficiente para demover a aceleração de processos excludentes, ou seja, além da criação de proteções legais são necessárias capacidade e vontade política para implementar políticas públicas e mobilização da sociedade para exigir seu cumprimento.

\title{
3. AS POLÍTICAS EDUCACIONAIS BRASILEIRAS E A EDUCAÇÃO ESCOLAR DAS PESSOAS COM DEFICIÊNCIA
}

As políticas educacionais brasileiras são influenciadas pela globalização mundial e suas consequências para os países em desenvolvimento, seguindo orientações estabelecidas pelos organismos internacionais que formulam as regras de funcionamento da economia, diretamente relacionada com os demais setores estratégicos de crescimento do país, sendo a educação um dos principais. Nas palavras de Neves:

\begin{abstract}
A política educacional neoliberal, a política do bloco no poder nos anos de 1990 segue, de um modo geral, as mesmas diretrizes neoliberais das políticas sociais em seu conjunto, ou seja: redução dos gastos públicos, focalização das ações governamentais, descentralização dos encargos e participação da sociedade na sua operacionalização (2007, p. 213).
\end{abstract}

Em uma sociedade na qual a escola não foi pensada para todos, a emergência de inúmeras questões relacionadas ao acesso, permanência e aprendizagem para toda a diversidade humana, traz à tona conflitos e convergências de interesses, culminando na participação ou na subordinação de pessoas em processos de desenvolvimento e formação.

A intenção de universalizar o ensino fundamental brasileiro, por exemplo, pode ser avaliada como um ponto positivo, afinal é importante que um país envide esforços para escolarizar a sua população, entretanto outros segmentos populacionais foram prejudicados em face da focalização nessa etapa da educação básica. $\mathrm{O}$ investimento prioritário nessa etapa segue as diretrizes da política educacional neoliberal, legitimando as relações sociais de produção e formando para o trabalho simples (NEVES, 2007). Além disso, é inegável que a expansão da escola para a faixa etária de 6 a 14 anos não foi acompanhada da melhoria da qualidade da educação brasileira.

O que dizer da construção dos chamados sistemas educacionais inclusivos? Se a escola fosse mesmo de todos, desde a estrutura física, se as diferenças, os tempos e as formas de aprendizagem fossem respeitadas, se fossem valorizadas as múltiplas 
linguagens, se os professores fossem formados para lidar com todas as capacidades humanas e se no espaço escolar a formação integral humana fosse prioridade, essa construção não seria enfatizada. Ainda assim, mesmo com a presença das pessoas com deficiência na escola, seria preciso avaliar com regularidade se de fato as funções da escola estão sendo cumpridas.

O acesso, a permanência e o aprendizado dos alunos com deficiência em espaços institucionais públicos, na atualidade, refletem como a educação especial foi construída no contexto das políticas públicas. Segundo Silva (2000), quando analisamos as políticas implementadas na área da educação especial, observa-se que o modelo adotado é quase sempre o da terceirização, com financiamento público às iniciativas privadas. As instituições privadas sem fins lucrativos, filantrópicas e assistenciais influenciam os rumos da política educacional para esse segmento da população e seu foco de atuação.

Na década de 1990 ocorreram reformas que atingiram todos os setores da educação, dentre esses a educação especial. A Secretaria de Educação Especial foi extinta no governo Fernando Collor de Melo (1990-1992) e suas funções remanejadas para a Secretaria Nacional de Educação Básica. No governo Itamar Franco (1992-1995) foi recriada a Secretaria de Educação Especial, rebatizada pela sigla SEESP, permanecendo assim até maio de 2011 (GARCIA e MICHELS, 2011).

O documento intitulado Política Nacional de Educação Especial (1994) foi organizado pelo Ministério da Educação para fundamentar e orientar

o processo global da educação de pessoas portadoras de deficiências, de condutas típicas e de altas habilidades, criando condições adequadas para o desenvolvimento pleno de suas potencialidades, com vistas ao exercício consciente da cidadania (p.45).

Na ocasião era considerado aluno da educação especial

aquele que, por apresentar necessidades próprias e diferentes dos demais alunos no domínio das aprendizagens curriculares correspondentes à sua idade, requer recursos pedagógicos e metodologias educacionais específicas. Genericamente chamados de portadores de necessidades educativas especiais, classificam-se em: portadores de deficiência (mental, visual, auditiva, física, múltipla), portadores de condutas típicas (problemas de conduta) e portadores de altas habilidades (superdotados) (Idem, p.13).

Nesse documento estava estabelecido que a educação especial deveria nortear suas ações pedagógicas pelos seguintes princípios: Normalização, Integração, Individualização, Sociológico da Interdependência, Epistemológico da Construção do Real, Efetividade dos Modelos de Atendimento Educacional e Ajuste Econômico com a Dimensão Humana. Consoantes com os princípios, objetivos geral e específicos foram elencadas diretrizes para materialização das concepções apresentadas, dentre as quais está o apoio ao "sistema regular de ensino para a integração dos educandos com necessidades especiais" (Idem, p.58).

Em 1994, também foi aprovada a Declaração de Salamanca na Espanha, que trouxe à tona naquele momento o surgimento de "um dilema conceitual e de fundamentação de política" (GARCIA e MICHELS, 2011, p.108), devido à substituição do termo de integração por inclusão. A Declaração de Salamanca oportunizou uma ampliação na 
discussão sobre o conceito de necessidades educacionais especiais e pontuou a inclusão como um aspecto importante do progresso das políticas educacionais.

Na Lei de Diretrizes e Bases da Educação Nacional, Lei n. 9.394/96, a educação especial é tratada em três artigos de um capítulo específico e está definida como modalidade de ensino destinada aos educandos com necessidades especiais, preferencialmente na rede regular de ensino, com a garantia de que, em virtude de determinadas condições específicas do aluno, podem ser ofertadas modalidades de atendimento fora da classe comum da rede regular. O termo "preferencialmente" abriu a possibilidade de o ensino continuar nas instituições especializadas e não somente na rede regular.

Outra questão a ser destacada diz respeito aos serviços especializados que podem ser acionados quando existir necessidade, porém não há esclarecimentos sobre quem define essa necessidade. Para Garcia e Michels (2011), a reforma educacional que ocorreu na educação especial, nos anos 1990, foi ambígua, pois por um lado o Governo Federal traçou as políticas que objetivaram a integração das pessoas com necessidades especiais, por outro delegou aos Estados, Municípios e às organizações não governamentais as medidas que assegurariam tal política.

Correspondendo a uma movimentação global em torno da divulgação de uma perspectiva inclusiva para a educação, no início do ano 2000 importantes documentos internacionais foram editados, inclusive a Convenção Interamericana para a Eliminação de Todas as Formas de Discriminação contra as Pessoas Portadoras de Deficiência, conhecida como Convenção de Guatemala, reconhecida no Brasil pelo Decreto n. 3.956/2001. O intuito foi reafirmar o direito da pessoa com deficiência, entre eles o direito de não ser discriminada em virtude da deficiência. Nessa ocasião, a deficiência passou a ser enfatizada como uma restrição causada ou agravada pelo ambiente econômico e social, influenciado pelas diretrizes do modelo social de deficiência.

A Resolução CEB/CNE n. 2/2001, ao instituir as Diretrizes Nacionais para a Educação Especial na Educação Básica, buscou normatizar no Brasil as premissas inclusivas do novo modelo. Entre as mudanças, destaca-se a demarcação da terminologia "alunos com necessidades especiais", definidos como todos aqueles que apresentavam dificuldades de aprendizagem, com ou sem correlação com questões orgânicas.

Essa elucidação, seguindo as indicações da Declaração de Salamanca, colocou o foco na atenção para uma diversidade de sujeitos, muitos dos quais fora do escopo de atuação da Educação Especial. As diretrizes, com caráter de lei, passam a regulamentar os artigos presentes na LDB 9.394/96. No documento observa-se que foi suprimida a palavra "preferencialmente" e foi acrescentada a noção de que os alunos da Educação Especial poderão, "extraordinariamente", serem atendidos em classes ou escolas especiais. Apesar da mudança no texto legal, "manteve-se a histórica lógica dual integrado/segregado, modificando, contudo, sua intensidade" (GARCIA E MICHELS, 2011, p. 108).

Em 2007 o Brasil torna-se signatário da Convenção Internacional sobre os Direitos das Pessoas com Deficiência, promulgada no Brasil por meio do Decreto n. 6.949/2009, que pode ser considerada um importante tratado internacional de direitos humanos, no qual houve ampla participação de instituições e movimentos sociais organizados em defesa dos direitos das pessoas com deficiência. Lopes afirma que "a Convenção e o Protocolo Facultativo foram aprovados, tanto na Câmara dos Deputados quanto no Senado Federal, com o quórum qualificado determinado e na forma definida pela EC 45/04, o que os torna equivalentes a uma emenda constitucional" (2009, p. 74). 
Sassaki (2008) comenta o artigo 24 da Convenção que dispõe sobre o direito à educação exigindo dos países envolvidos a garantia de sistemas educacionais inclusivos nos quais as crianças tenham possibilidades de participação e desenvolvimento, mediante a organização da escola em termos de acessibilidade, arquitetura, comunicação, métodos e técnicas, instrumentos, programas e atitudes. Percebe-se então a importância desse documento legal, que contribuiu para a mudança do acesso à escola a todas as pessoas.

É possível constatar que o movimento de inserção das pessoas com deficiência na escola regular veio ganhando força ao longo da década de 1990, entretanto somente em 2008 é divulgada a Política Nacional de Educação Especial na perspectiva da Educação Inclusiva, que tornou-se um documento de referência na política educacional no Brasil.

O Decreto n. 6.571/2008 dispunha sobre o Atendimento Educacional Especializado (AEE), que é o atendimento ao público alvo da educação especial no contra turno da escola em Salas de Recursos Multifuncionais e garantia o cômputo das matrículas dos alunos da escola pública que estivessem no AEE, como dupla matrícula para efeitos de distribuição do FUNDEB. Essa decisão política de financiamento da educação especial foi considerada impulsionadora da presença das pessoas com deficiência na escola regular até a revogação desse instrumento legal pelo Decreto n. 7.611/2011, que privilegia as instituições especializadas privadas, ao permitir o duplo cômputo da matrícula dos alunos que estiverem nessas instituições e no AEE.

Desde 2011, a Educação Especial está alocada na Diretoria de Políticas de Educação Especial da Secretaria de Educação Continuada, Alfabetização, Diversidade e Inclusão do Ministério da Educação. A Secretaria tem como principais programas e ações o Programa Escola Acessível, Transporte Escolar Acessível, Sala de Recursos Multifuncionais, Formação Continuada de Professores na Educação Especial, Benefício de Prestação Continuada (BPC) na Escola, Acessibilidade à Educação Superior, Educação Inclusiva: Direito à Diversidade, Livro Acessível, Prolibras, Centro de Formação e Recursos, Prêmio Experiências Educacionais Inclusivas e Comissão Brasileira do Braille.

Nesse mesmo ano de 2011, o governo federal lançou o Plano Nacional dos Direitos da Pessoa com Deficiência, o Plano Viver sem Limite, que tem como objetivo principal promover, por meio da integração e articulação de políticas, programas e ações, o exercício pleno e equitativo dos direitos das pessoas com deficiência, que deverá ser executado pela União, em colaboração com Estados, Distrito Federal, municípios e sociedade.

São quatro os eixos de atuação do referido plano: Acesso à Educação, Atenção à Saúde, Inclusão Social e Acessibilidade. Como diretrizes macro o plano apresenta a garantia de um sistema educacional inclusivo e de equipamentos públicos de educação acessíveis para as pessoas com deficiência, inclusive por meio de transporte adequado. $\mathrm{Na}$ tabela a seguir é possível observar a previsão da distribuição dos recursos federais para a execução das ações de cada um dos eixos:

Tabela 1 - Volume de Recursos Federais (2011-2014)

\begin{tabular}{|c|c|}
\hline Área & Recursos \\
\hline Acesso à Educação & $\mathrm{R} \$ 1.840 .865 .303,00$ \\
\hline Atenção à Saúde & $\mathrm{R} \$ 1.496 .647 .714,00$ \\
\hline Inclusão Social & $72.240 .000,00$ \\
\hline Acessibilidade & $\mathrm{R} \$ \quad 98.500 .000,00$ \\
\hline Total & $R \$ 7.608 .253 .018 .00$ \\
\hline
\end{tabular}

Fonte: Site SDH/PR 
As metas de 2011 a 2014 do eixo Acesso à Educação dizem respeito à implementação de 15.000 salas de Recursos Multifuncionais e aquisição de 3.000 kits de atualização dessas salas; 42.000 escolas previstas para serem atendidas pelo Programa Dinheiro Direto na Escola para Acessibilidade; aquisição de 2.609 veículos escolares acessíveis; vagas do Bolsa Formação do PRONATEC, destinadas prioritariamente às pessoas com deficiência; $100 \%$ das universidades federais com projetos para acessibilidade apoiados; contratação de 690 professores, tradutores e intérpretes de libras, criação de 27 Cursos de Letras/Libras e 12 Cursos de Pedagogia na perspectiva bilíngue; ampliação do quantitativo de pessoas de 0 a 18 anos beneficiárias do BPC matriculadas na Escola para 72.000 .

Consultando o Observatório do Viver sem Limite é possível relacionar que das 15.000 salas de recursos previstas, 13.360 foram implementadas e 14.999 escolas receberam o kit para atualização dessas salas; das 42.000 escolas previstas para serem atendidas com Dinheiro Direto na Escola para Acessibilidade, 40.316 escolas foram atendidas; dos 2.609 veículos escolares acessíveis previstos, 2.304 veículos foram adquiridos e 1.874 foram entregues a 1.541 municípios; 17.913 matrículas foram realizadas no Programa de Capacitação Técnica até dezembro de 2014; recursos financeiros para as 59 universidades federais foram disponibilizados em suas matrizes orçamentárias, atingindo os $100 \%$ previstos; dos 27 cursos de Letras/Libras previstos, foram criados 20 cursos; sobre o BPC na Escola, a informação obtida é que o número de beneficiários aumentou, totalizando 329,8 mil.

Um item que não teve o alcance proposto foi a criação de 12 Cursos de Pedagogia na perspectiva bilíngue, tendo em vista que somente em dezembro de 2014, o Instituto Federal de Goiás lançou um edital de vestibular para o Curso de Pedagogia Bilíngue, com funcionamento previsto para 2015. Anteriormente ao Plano Viver sem Limite existia apenas um curso dessa natureza no Instituto Nacional de Educação para Surdos no Rio de Janeiro, que iniciou seu funcionamento em 2006.

A Lei 12.796/2013 alterou aspectos da LDB 9.394/1996 em relação à educação especial, modificando a nomenclatura anteriormente utilizada para designar seu público alvo, pois a LDB referia-se aos educandos com necessidades especiais e com a redação dada pela legislação de 2013, passa a referir-se aos educandos com deficiência, transtornos globais do desenvolvimento e altas habilidades ou superdotação.

Em todas as conquistas mencionadas a presença dos conselhos de defesa dos direitos e os movimentos sociais são de fundamental importância na luta e controle social das ações e programas governamentais e no cumprimento do disposto nas legislações educacionais. Nessa perspectiva, Mendes afirma que "Assim, a grande e conjunta luta é a de construir uma escola brasileira pública de melhor qualidade para todos, e ao mesmo tempo, garantir que as especificidades da população alvo da educação especial sejam respeitadas (2010, p.107).

Analisar a evolução das matrículas dos alunos com deficiência na educação básica permite a verificação do acesso à escola regular. Para tanto, pode-se recorrer ao Resumo Técnico do Censo da Educação Básica 2013, que aponta um aumento de $25 \%$ das matrículas no período de 2007 a 2012. No mesmo período analisado, houve um crescimento de $102,77 \%$ dos alunos com deficiência na escola regular e uma diminuição de $42,70 \%$ de matrículas nas escolas e classes especiais.

De acordo com os estudos de Laplane (2014) a maior concentração desses alunos está no ensino fundamental, com índices de 70,86\% em 2007 e 62,17\% em 2012. A autora 
cita o exemplo do município de Campinas-SP para esclarecer que, segundo depoimentos de professores, gestores e pais do referido município, a necessidade de profissionais como cuidadores ou mesmo professores de educação especial e a ausência desses nas escolas, seria um impedimento para os alunos frequentarem a educação infantil. Em relação ao ensino médio, a autora aponta o problema do acesso ao conhecimento, considerando que a maior parte dos alunos matriculados tem deficiência intelectual. Esses alunos acabam permanecendo no ensino fundamental e depois vão para a Educação de Jovens e Adultos ou para instituições especializadas.

Como organizar a escola de forma a garantir que todos aprendam respeitando a forma como cada um aprende, com o estabelecimento pelo governo federal de avaliações nacionais do ensino fundamental ao ensino superior, Provinha Brasil, Sistema de Avaliação da Educação Básica (SAEB), no qual estão a Avaliação Nacional da Educação Básica (ANEB), Avaliação Nacional do Rendimento Escolar, a conhecida Prova Brasil, e a Avaliação Nacional da Alfabetização (ANA), Exame Nacional do Ensino Médio (ENEM), Exame Nacional de Desempenho de Estudantes (ENADE) e com a criação do Índice de Desenvolvimento da Educação Básica (IDEB), que leva os profissionais da escola a preocuparem-se mais com o desempenho dos alunos nos referidos testes do que com a formação integral humana? Ao exercer seu papel de "Grande Supervisor" (Arelaro, 2003, p.31) com o objetivo de avaliar o desempenho dos sistemas educacionais "para identificar 'pontos de estrangulamento' a serem corrigidos, visando à garantia de uma maior produtividade desse mesmo sistema" (Idem), o governo estimula a competição entre escolas e entre professores e não garante a melhoria da qualidade da educação pública brasileira.

\section{CONSIDERAÇÕES FINAIS}

Para compreender a educação escolar das pessoas com deficiência no contexto brasileiro é necessário, inicialmente, atentar para as diferentes concepções de deficiência e sua relação com o exercício e a garantia dos direitos humanos e com as políticas públicas e sociais.

No Brasil, o sistema capitalista e a ideologia neoliberal têm dado o tom nas relações humanas, mediando interesses conflitantes de pessoas pertencentes a classes sociais distintas, o que tem levado a organização das pessoas em situação menos favorável economicamente em grupos específicos para lutar pela defesa de seus direitos. Entende-se essas organizações como legítimas e necessárias, contudo se essa luta não for unificada, dificilmente acontecerá uma transformação social, podendo acontecer apenas reformas pontuais.

Em suma, a luta pelos direitos das pessoas com deficiência não pode estar descolada da luta por melhores condições de vida para todos, tendo em vista que as políticas sociais focalizadas terão limites de alcance, na medida em que não forem realizadas ações estruturais que promovam avanços em direção à participação de todos.

Nessa direção, Jannuzzi reflete sobre a importância do legado de uma perspectiva de análise crítica sobre a educação, assim como sobre a educação das pessoas com deficiência:

Em educação especial há a defesa da inserção e da qualidade do ensino dos deficientes como influenciadores nesse processo de transformação social, na medida em que o torna consciente dos condicionamentos 
existentes e proporciona-lhes meios de se apropriarem dos conhecimentos necessários à vida e à transformação social (2012, p.162).

O controle e o acompanhamento da aplicação dos recursos públicos, oriundos do pagamento de impostos, precisam ser aperfeiçoados e a participação popular nas decisões fundamentais que lhes dizem respeito, deve ser exercitada, pois as políticas e programas implementados até agora não puderam garantir uma escola pública, gratuita e de qualidade para todos.

Conforme os avanços nas legislações nacionais relacionadas ao direito à educação, são inegáveis as conquistas de acesso e a chegada da chamada inclusão de todos na escola. Todavia, é inegável também que esse movimento caminha a passos lentos, pois nem todos estão no espaço escolar e quando estão, pode lhes ser subtraído o direito de aprender, quando não houverem as condições necessárias para que a aprendizagem aconteça.

A história da educação escolar das pessoas com deficiência é uma história permeada pela segregação e assistencialismo, na qual o setor privado teve e ainda tem presença marcante, movido pela ausência do poder público na oferta direta de educação. Mudar essa história é também e não somente cumprir o disposto na legislação, em relação à educação como direito de todos, sem qualquer distinção, discriminação ou preconceito com os seres humanos.

E para que o direito à educação seja de fato concretizado os profissionais que atuam na educação especial e o acúmulo de conhecimentos produzidos nessa área tem um papel importante, tanto para os alunos que estão na escola comum, como para os que estão atendimento educacional especializado, como para aqueles que estão em classes ou escolas especiais.

\section{REFERÊNCIAS}

ARELARO, Lisete Regina Gomes. Direitos Sociais e Política Educacional: alguns ainda são mais iguais que outros. In: SILVA, Shirley. VIZIM, Marli. Políticas Públicas: educação, tecnologias e pessoas com deficiências. Campinas, SP: Mercado de Letras; Associação de Leitura do Brasil (ABL), 2003.

AUGUSTIN, Ingrid. Modelos de Deficiência e suas implicações na Educação Inclusiva. Trabalho apresentado na IX ANPED SUL. Disponível em: http://www.ucs.br/etc/conferencias/index.php/anpedsul/9anpedsul/paper/viewFile/1427/65 5 Acesso em: 12.01.2015.

BARNES, Colin. Discapacidad, política y pobreza en el contexto del "Mundo Mayoritario". In: Política y Sociedad, 2010, Vol. 47, n. 1: 11-25.

BRASIL, Cartilha do Censo 2010 - Pessoas com Deficiência. Luzia Maria Borges Oliveira. Secretaria de Direitos Humanos da Presidência da República (SDH/PR) / Secretaria Nacional de Promoção dos Direitos da Pessoa com Deficiência (SNPD) / Coordenação Geral do Sistema de Informações sobre a pessoa com Deficiência; Brasília: SDH-PR/SNPD, 2012.

BRASIL. Constituição da República Federativa do Brasil. Brasília, DF: Senado, 1988.

BRASIL, Decreto no 6.571, de 17/09/2008. Dispõe sobre o Atendimento Educacional Especializado, regulamenta o parágrafo único do art. 60 da Lei n ${ }^{\circ}$ 9.394, de 20 de 
dezembro de 1996, e acrescenta dispositivo ao Decreto $\mathrm{n}^{\circ} 6.253$, de 13 de novembro de 2007.

BRASIL, Decreto no 3.956, de 08/10/2001. Dispõe sobre a Educação Especial, o Atendimento Educacional Especializado e dá outras providências.

BRASIL, Decreto n ${ }^{\mathbf{0}}$ 3.956, de 08/10/2001. Promulga a Convenção Interamericana para a Eliminação de Todas as Formas de Discriminação contra as Pessoas Portadoras de Deficiência, 2001.

BRASIL, Decreto no 6.949, de 25/08/2009. Promulga a Convenção Internacional sobre os Direitos das Pessoas com Deficiência e seu Protocolo Facultativo, assinados em Nova York, em 30 de março de 2007.

BRASIL, Lei $\mathbf{n}^{\mathbf{0} 12.796}$, de 4 de abril de 2013. Altera a Lei $\mathrm{n}^{\mathbf{0}}$ 9.394, de 20 de dezembro de 1996, que estabelece as diretrizes e bases da educação nacional, para dispor sobre a formação dos profissionais da educação e dar outras providências.

BRASIL, Lei n⿳0 8.069, de 13 de julho de 1990. Dispõe sobre o Estatuto da Criança e do Adolescente e dá outras providências.

BRASIL, Lei no 9.394, de 20 de dezembro de 1996. Estabelece as Diretrizes e Bases da Educação Nacional.

BRASIL, Lei no 11.494, de 20 de junho de 2007. Fundo de Manutenção e Desenvolvimento da Educação Básica e de Valorização dos Profissionais da Educação.

BRASIL, Lei no 9.424, de 24 de dezembro de 1996. Fundo de Manutenção e Desenvolvimento do Ensino Fundamental e de Valorização do Magistério.

BRASIL, Ministério da Educação. Política Nacional de Educação Especial. Brasília: MEC/SEESP, 1994.

BRASIL, Ministério da Educação. Política Nacional de Educação Especial na Perspectiva da Educação Inclusiva. Brasília: MEC/SEESP, 2008.

BRASIL, Ministério da Educação. Resolução CNE/CEB no 2, de 11 de setembro de 2001. Institui as Diretrizes Nacionais para a Educação Especial na Educação Básica, 2001.

BRASIL, Secretaria Especial dos Direitos Humanos da Presidência da República. Secretaria Nacional de Promoção dos Direitos da Pessoa com Deficiência. Viver sem Limite - Plano Nacional dos Direitos da Pessoa com Deficiência. Brasília, 2012.

BRASIL, Secretaria Especial dos Direitos Humanos da Presidência da República. Secretaria Nacional de Promoção dos Direitos da Pessoa com Deficiência. Observatório do Viver sem Limite - Plano Nacional dos Direitos da Pessoa com Deficiência. Brasília, 2012. Disponível em: www.sdh.gov.br/assuntos/.../observatorio Acesso em: 22.01.2015.

CARNEIRO, Ricardo e SOUZA, José Moreira de. Universalismo e Focalização na Política de Atenção à Pessoa com Deficiência. In: Saúde e Sociedade, São Paulo, v.16, n.3, p.69-84, 2007.

DINIZ, Débora. Deficiência e Políticas Sociais - entrevista com Colin Barnes. In: SER Social, Brasília, v. 15, n. 32, p. 237-251, jan./jun. 2013.

GARCIA, Rosalba Maria Cardoso; MICHELS, Maria Helena. A Política de Educação Especial no Brasil (1991-2011): uma análise da produção do GT15 - Educação Especial da ANPED. In: Rev. Bras. Ed. Esp., Marília, v.17, p.105-124, maio-ago, 2011. Edição 
Especial.

GATJENS, Luiz Fernando Astorga. A situação das pessoas com deficiência na América Latina e no Caribe - Brasília, 30 de novembro de 2007; Tradução: Romeu Kazumi Sassaki. Disponível em: www.planetaeducacao.com.br/portal/artigo.asp?artigo=1385

JANNUZZI, Gilberta de Martino. A educação do deficiente no Brasil: dos primórdios ao início do século XXI. 3. ed. rev. Campinas, SP: Autores Associados, 2012.

LAPLANE, Adriana Lia Friszman de. Condições para o ingresso e permanência de alunos com deficiência na escola. In: Cadernos Cedes, Campinas, v. 34, n. 93, maio-ago. 2014.

LOPES, Laís Vanessa Carvalho de Figueirêdo Lopes. Convenção sobre os Direitos das Pessoas com Deficiência da ONU, seu Protocolo Facultativo e a Acessibilidade.

Dissertação de Mestrado em Direito. Pontifícia Universidade Católica de São Paulo, 2009.

MENDES, Enicéia Gonçalves. Breve Histórico da Educação Especial no Brasil. In:

Revista Educación y Pedagogía, vol.22, núm. 57, mayo-agosto, 2010.

NEVES, Lúcia Maria Wanderley. Brasil Século XXI: propostas educacionais em disputa. In: LOMBARDI, José; SANFELICE, José Luís. Liberalismo e Educação em debate. Campinas, SP: Autores Associados, Histedbr, 2007.

PATTO, Maria Helena Souza. Para uma Crítica da Razão Psicométrica. In: Psicologia USP, vol. 8, n. 1, São Paulo, 1997.

SASSAKI, Romeu Kazumi. Artigo 24 - Educação. In: RESENDE, Ana Paula Crosara. VITAL, Flávia Maria de Paiva. A Convenção sobre os Direitos das Pessoas com Deficiência Comentada. Brasília: Secretaria Especial dos Direitos Humanos, Coordenadoria Nacional para Integração da Pessoa Portadora de Deficiência, 2008.

SILVA, Shirley. Educação Especial: um esboço de política pública. Tese de Doutorado em Educação. Faculdade de Educação da Universidade de São Paulo, 2000.

UNESCO. Declaração de Salamanca e linha de ação sobre necessidades especiais. Salamanca/Espanha 1994.

\footnotetext{
${ }^{1}$ Professora da Universidade Federal do Pará. Doutoranda do Programa de Pós-Graduação em Educação da Faculdade de Educação da Universidade de São Paulo. E-mail: roseanerabelo@ yahoo.com.br

${ }^{2}$ Professora da Universidade Federal do Maranhão. Doutoranda do Programa de Pós-Graduação em Educação da Faculdade de Educação da Universidade de São Paulo. E-mail: thaisacfl@gmail.com
}

Recebido: jun2015 $\quad$ Aprovado: jul/2015 